\title{
Effect of Stabilization Heat Treatment on Time-Dependent Polarization Losses in Sintered Nd-Fe-B Permanent Magnets
}

\author{
M. Haavisto ${ }^{1}$, H. Kankaanpää ${ }^{2}$, T. Santa-Nokki ${ }^{1}$, S. Tuominen $^{1}$ and M. Paju $^{1}$ \\ ${ }^{1}$ Magnet Technology Centre, Prizztech Ltd., Pori, Finland \\ ${ }^{2}$ Neorem Magnets Oy, Ulvila, Finland
}

\begin{abstract}
Some companies in the motor and generator industry utilizing sintered NdFeB magnets have adopted pre-ageing heat treatment in order to improve the stability of the magnets. The parameters of this stabilization heat treatment are based mainly on assumptions rather than on any published research results. In this work, the effects of pre-ageing treatment on the time-dependent polarization losses of two different types of commercial sintered $\mathrm{NdFeB}$ magnets were studied. The material showing the squarer $\mathrm{J}(\mathrm{H})$ curve did not benefit from the pre-ageing treatment, since it seems to be stable under a certain critical temperature. In contrast, a stabilizing effect was observed in the material showing rounder $\mathrm{J}(\mathrm{H})$ curve. After the stabilization heat treatment, the polarization of the magnets was found to be at lower level, but unchanged over a certain period of time. The length of this period depends on the temperature and the duration of the pre-ageing treatment. In addition, our analysis reveals that the stabilization heat treatment performed in an open circuit condition does not stabilize the magnet uniformly.
\end{abstract}

\section{Introduction}

Stabilizing heat treatment also known as pre-aging heat treatment is a method used in order to improve the thermal stability of permanent magnets. This means that the magnets are exposed to a higher temperature than their maximum operating temperature before being installed to the application. However, there are not many published papers about the effects of such heat treatment on the subsequent loss behaviour of sintered $\mathrm{NdFeB}$ magnets. Radiation-induced demagnetization is claimed to decrease due to this kind of thermal stabilization [1]. The pre-ageing heat treatment that caused $-0.69 \%$ decrease to the polarization was found to be sufficient to decrease the subsequent demagnetization in the electron beam exposure close to zero.

The effects of stabilization heat treatment on SmCo based magnets have been studied previously [2-3]. As long as the stabilization treatment is performed at moderate temperatures, the effects are purely due to domain wall motion and a stabilizing effect is attained [2]. The remanence of the magnets was reduced proportionally during the stabilization treatment. In [3], the time-dependent demagnetization of SmCo magnets within a three-year measurement period was found to decrease to about $0.3 \%$ due the two-hour pre-ageing treatment.

The principal idea of thermal stabilization is that the magnetization of the weakest domains in the magnet is flipped due to thermal activation. The domains that maintain their original magnetization state, despite thermal exposure, are assumed to be stable at temperatures below the stabilization temperature. Based on this assumption, stabilization heat treatment is introduced as a part of the production process in some companies utilizing sintered $\mathrm{NdFeB}$ magnets. The exposure temperature and the duration of the heat treatment are more or less chosen on the basis of rough estimates.

In this work we studied the effect of the pre-ageing heat treatment on the time-dependent polarization losses in sintered $\mathrm{NdFeB}$ permanent magnets. The effect of the $\mathrm{J}(\mathrm{H})$ curve squareness of the material on the thermal stabilization was also studied.

\section{Method}

Test materials were commercial sintered $\mathrm{NdFeB}$ magnets produced by Neorem Magnets Oy. Materials were specified according to their measured $\mathrm{B}(\mathrm{H})$ curves.

Two different materials were chosen from previously tested materials [4-6]. The criteria of the selection was that the coercivities of the materials were close to each other at a certain elevated temperature at which a small knee also appeared in the second quadrant of the $\mathrm{B}(\mathrm{H})$ curves. Additionally, the shape of the $\mathrm{J}(\mathrm{H})$ curves was expected to be different. Material 2 in [4] was 
chosen as material $\mathrm{A}$ in this research and material 2 in [5] as material B. At $120^{\circ} \mathrm{C}$ the difference in the coercivities of these materials is less than $3 \%$.

The magnetic properties of the samples were determined by the $\mathrm{B}(\mathrm{H})$ curve measurements carried out with Magnet Physik Permagraph C-300. The properties of the studied materials at room temperature are presented in Table 1 and at $120^{\circ} \mathrm{C}$ in Table 2 . The $\mathrm{B}(\mathrm{H})$ and $\mathrm{J}(\mathrm{H})$ curves measured at $120^{\circ} \mathrm{C}$ and $130^{\circ} \mathrm{C}$ are presented in figure 1.

The squareness factor (SF) is used as a measure for the squareness of the $\mathrm{J}(\mathrm{H})$ curve.

$$
S F=\frac{H_{k}}{H_{C i}}
$$

where $H_{c i}$ is the intrinsic coercivity of the material and $H_{k}$ refers to the field at which $10 \%$ of the remanence is lost (= field at $90 \%$ of $B_{r}$ ) [6].

The rectangular-shaped samples were $10 \times 10 \mathrm{~mm}$ in size, with varying heights (the direction of magnetization). The heights of material $\mathrm{B}$ samples were 4.1, 4.9 and $5.6 \mathrm{~mm}$. These correspond to permeance coefficient $\left(\mathrm{P}_{c}\right)$ values of $1.0,1.2$ and 1.4 when determined from the dimensions of the samples [7]. The height of material A samples was $4.6 \mathrm{~mm}$ leading to a $\mathrm{P}_{\mathrm{c}}$ of 1.1 .

The testing method for studying the time-dependent demagnetization is described in detail in [4]. The ageing temperature in this study was $120^{\circ} \mathrm{C}$. Polarization loss measurements were performed with a Helmholtz coil at room temperature. Losses are presented as a percentage of the original polarization values measured straight after magnetization. Each loss value is an average of the measured losses of five identical samples.

The stabilization heat treatment prior to ageing was performed at $130^{\circ} \mathrm{C}$ for a duration of one hour.

Table 1. Properties of studied materials.

\begin{tabular}{|c|c|c|c|c|}
\hline Material & $\begin{array}{c}\text { Room } \\
\text { temp. } \\
\text { coercivity } \\
\mathbf{H}_{\text {ci }} \\
{[\mathbf{k A} / \mathbf{m}]}\end{array}$ & $\begin{array}{c}\text { Room } \\
\text { temp. } \\
\text { remanence } \\
B_{r}[T]\end{array}$ & $\begin{array}{c}\text { Temp. } \\
\text { coeff. } \\
\alpha \text { of } \mathrm{B}_{\mathrm{r}} \\
(20- \\
\left.100^{\circ} \mathrm{C}\right) \\
{\left[\% /{ }^{\circ} \mathrm{C}\right]}\end{array}$ & $\begin{array}{c}\text { Temp. } \\
\text { coeff. } \\
\beta \text { of } \mathbf{H}_{\mathrm{ci}} \\
(20- \\
\left.100^{\circ} \mathrm{C}\right) \\
{\left[\%{ }^{\circ} \mathrm{C}\right]}\end{array}$ \\
\hline A & 1540 & 1.24 & -0.13 & -0.59 \\
\hline B & 1680 & 1.21 & -0.09 & -0.62 \\
\hline
\end{tabular}

Table 2. Properties of the materials at $120^{\circ} \mathrm{C}$.

\begin{tabular}{|c|c|c|c|c|}
\hline Material & $\begin{array}{c}\text { Coercivity } \\
\mathbf{H}_{\mathbf{c i}} \\
{[\mathbf{k A} / \mathbf{m}]}\end{array}$ & $\begin{array}{c}\text { Remanence } \\
\mathbf{B}_{\mathbf{r}}[\mathbf{T}]\end{array}$ & $\begin{array}{c}\mathbf{H}_{\mathbf{k}} \\
{[\mathbf{k A} / \mathbf{m}]}\end{array}$ & $\begin{array}{c}\text { Squareness } \\
\text { factor SF }\end{array}$ \\
\hline $\mathrm{A}$ & 677 & 1.08 & 656 & 0.97 \\
\hline $\mathrm{B}$ & 658 & 1.07 & 658 & 0.89 \\
\hline
\end{tabular}

The demagnetizing field inside the samples was calculated using FEM. The software used was Opera by Vector Fields. One eighth of the samples were modelled with magnetic properties: $\mathrm{B}_{\mathrm{r}}=1.2134 \mathrm{~T}, \mathrm{H}_{\mathrm{cb}}=924 \mathrm{kA} / \mathrm{m}$ and recoil permeability of 1.045 . Values are determined from the $\mathrm{B}(\mathrm{H})$ curve of material $\mathrm{B}$ at room temperature. $\mathrm{B}(\mathrm{H})$ curve was assumed to be linear. The analysis with non-linear $\mathrm{B}(\mathrm{H})$ curve measured at $120^{\circ} \mathrm{C}$ failed.

In order to study the distribution of the demagnetization, the magnetic flux density near the sample surface was scanned along the center line of the sample before and after the stabilization heat treatment. The measurements were performed with a Lakeshore gaussmeter, model 450 and Lakeshore MNA-1904-VH hall probe fixed perpendicular to the sample surface. The magnetic flux density was scanned across the sample at a distance of $0.2 \mathrm{~mm}$.

\section{Results and discussion}

\subsection{Polarization losses in stabilized and non- stabilized samples}

The polarization loss measurements were carried out for 10000 hours to be able to predict the long-term behaviour of the stabilized magnets. Figure 2 shows the detected losses as a function of time for the samples with an average $\mathrm{P}_{\mathrm{c}}=1.1$ and 1.2 for materials $\mathrm{A}$ and $\mathrm{B}$ respectively. The logarithmic trend lines [8] for losses are also plotted in figure 2 . The trend lines are lengthened to reach 260000 hours, which corresponds to an expected life-time of 30 years.

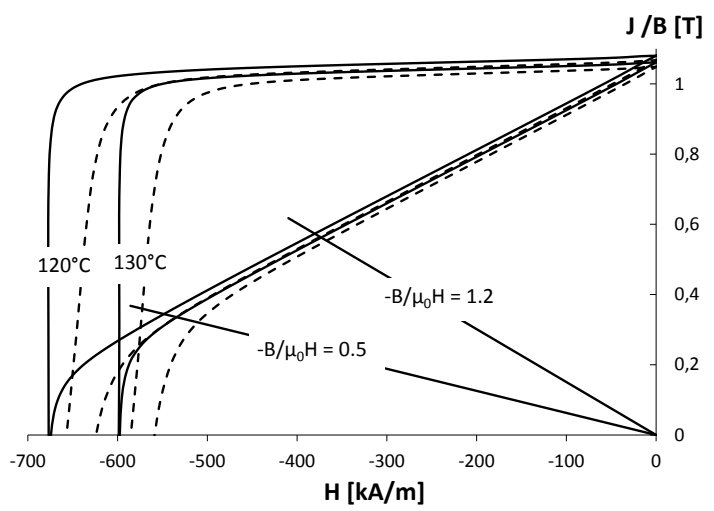

Fig. 1. $\mathrm{B}(\mathrm{H})$ and $\mathrm{J}(\mathrm{H})$ curves at $120^{\circ} \mathrm{C}$ and $130^{\circ} \mathrm{C}$ for materials A (solid line) and for material B (dashed line). Load lines 0.5 and 1.2 are also included.

The loss behaviour of material A magnets is similar in stabilized and non-stabilized samples. These two trend lines overlap and the estimate of the total loss after 30 years is less than $1 \%$ in both cases. This indicates that this type of magnet does not benefit from stabilization treatment. The loss behaviour of material B magnets, however, differs clearly depending on whether the samples were stabilized or not. Non-stabilized samples exhibit a decreasing loss trend, starting from a $1.7 \%$ loss after one hour's exposure and resulting in a loss estimate of $4.5 \%$ in 30 years. In contrast, stabilization treatment at $130^{\circ} \mathrm{C}$ causes a loss of approx. $3 \%$ and this state of magnetization remains until about 1000 hours when the samples are kept at $120^{\circ} \mathrm{C}$. At this point the decreasing loss trend of the non-stabilized samples is obtained and it 
seems that the subsequent loss trends overlap. Further measurement points would ensure this behaviour, but it is inconvenient to implement the measurements, since it requires years of exposure.

The effect of sample height on the loss behaviour of stabilized and non-stabilized samples produced from material B is presented in figure 3. All the samples exhibit similar loss trends, only the magnitudes of the initial as well as the subsequent time-dependent losses are different. The slope of the trend line and the initial loss in non-stabilized samples increases as the thickness of the sample decreases (figure 3 a). The stabilization treatment also causes increasing losses with decreasing magnet thickness (figure $3 \mathrm{~b}$ ). Subsequent exposure at a lower temperature does not cause any further loss until 1000 hours of exposure is reached. As the exposure is extended from 1000 to 10000 hours the losses turn to follow the trends of the non-stabilized samples (figure 3c). This is logical, since the stabilization heat treatment only partly demagnetizes the samples and does not affect the microstructure of the magnets. The same partial demagnetization occurs in the non-stabilized samples due to thermal activation over time. As the same demagnetized state is achieved regardless of the thermal history, the subsequent demagnetization behaviour is expected to be identical.

This shows that insufficient stabilization heat treatment will make the magnets stable only for part of the lifetime of the application. The usage of magnets exhibiting squarer $\mathrm{J}(\mathrm{H})$ curves would be more practical. According to this study, a squareness factor of 0.97 is sufficient to ensure stability over time and thus, preageing treatment is unnecessary. Our previous study [5] supports this conclusion.

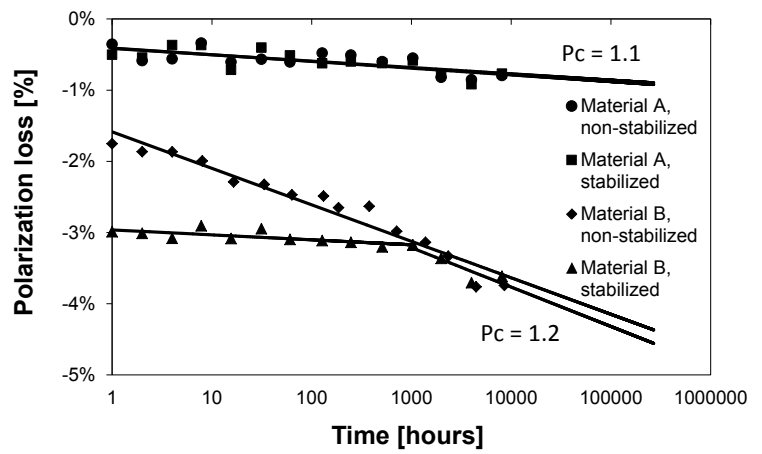

Fig. 2. Polarization losses as a function of time for stabilized and non-stabilized magnets produced from materials A and B. The dimensions of the samples were $10 \times 10 \times 4.6 \mathrm{~mm}$ in material A samples and $10 \times 10 \times 4.9 \mathrm{~mm}$ in material B samples.

\subsection{Partial demagnetization of stabilized magnets}

FEM models of the material B samples were generated in order to understand the partial demagnetization process occurring during the stabilization heat treatment. The variations of $-\mathrm{B}_{\mathrm{z}} / \mu_{0} \mathrm{H}_{\mathrm{z}}$ (often considered to be the same as $\mathrm{P}_{\mathrm{c}}$ ) in the samples before treatment are presented in figure 4. This figure reveals that $-\mathrm{B}_{\mathrm{z}} / \mu_{0} \mathrm{H}_{\mathrm{z}}$ or $\mathrm{P}_{\mathrm{c}}$ in actual fact varies dramatically inside the sample. The $\mathrm{P}_{c}$ reaches its minimum at the centre of top and bottom surfaces of the samples and falls to as low as approx. 0.5 in our samples. Figure $1 \mathrm{~b}$ shows that the working point of 0.5 is already slightly below the $\mathrm{B}(\mathrm{H})$ curve knee at $130^{\circ} \mathrm{C}$. Some initial loss in the samples from material B is thus expected.
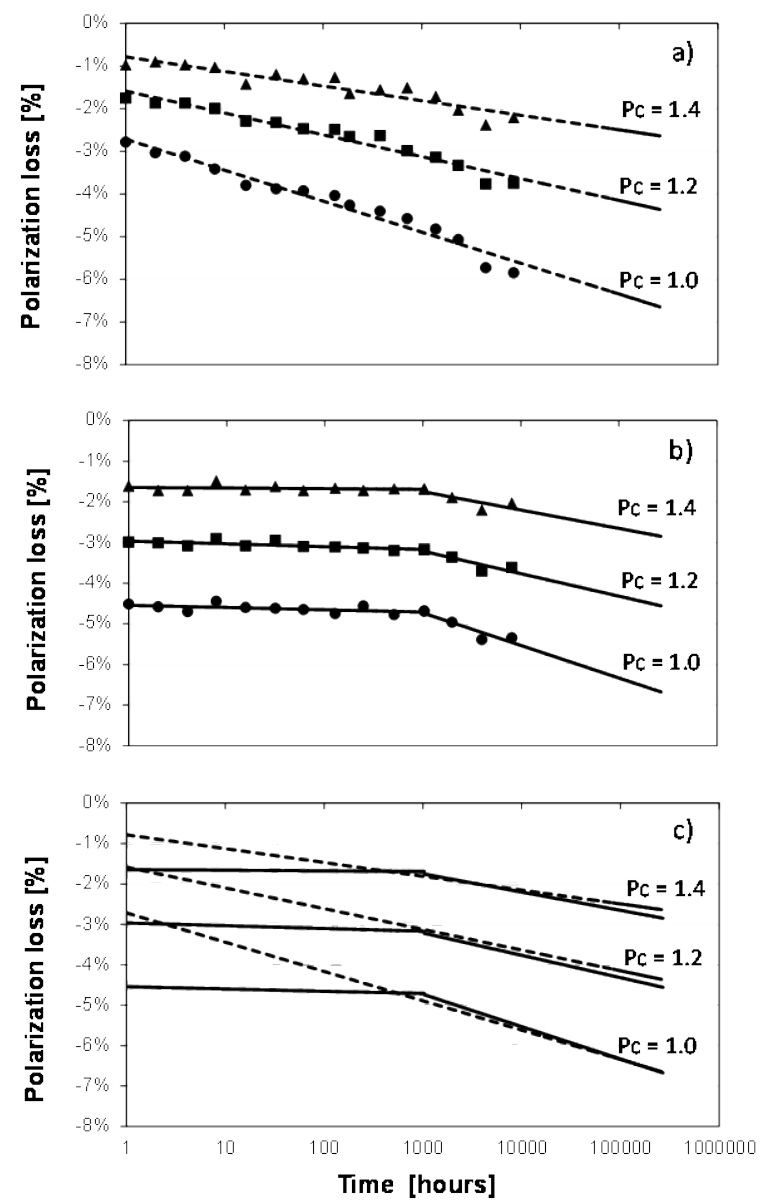

Fig. 3. Polarization losses in non-stabilized samples (a) and stabilized samples (b) (material B at $120^{\circ} \mathrm{C}$ ) and the combined trends of the two $(\mathrm{c})$.

The partial demagnetization is concentrated to the areas where $-\mathrm{B}_{\mathrm{z}} / \mu_{0} \mathrm{H}_{\mathrm{z}}$ is below about 0.55 i.e. close to the centres of the surfaces that are perpendicular to the magnetization direction. Figure 5 shows the magnetic flux density profiles measured on the top of this surface $\left(\mathrm{P}_{\mathrm{c}}\right.$ of the sample $\left.=1.0\right)$ before and after the stabilization treatment. The flux density is lower at the centre of the surface than at the edges.

The area falling below the knee point of $\mathrm{B}(\mathrm{H})$ curve is much larger in the case of the magnets of $4.1 \mathrm{~mm}$ in height (figure 4 a) than in the magnets of $5.6 \mathrm{~mm}$ in height (figure $4 \mathrm{c}$ ). Besides this, the difference in the minimum of $-\mathrm{B}_{\mathrm{z}} / \mu_{0} \mathrm{H}_{\mathrm{z}}$ explains the difference in the demagnetization states of different sized magnets after pre-ageing at $130^{\circ} \mathrm{C}$.

Correspondingly, the time-dependent demagnetization occurring in the non-stabilized samples is most likely to occur in the areas where $\mathrm{P}_{c}$ is close to the $\mathrm{B}(\mathrm{H})$ curve knee. This area is the largest in the lowest samples in height even after the initial demagnetization. This could also explain the greater demagnetization occurring over time. 


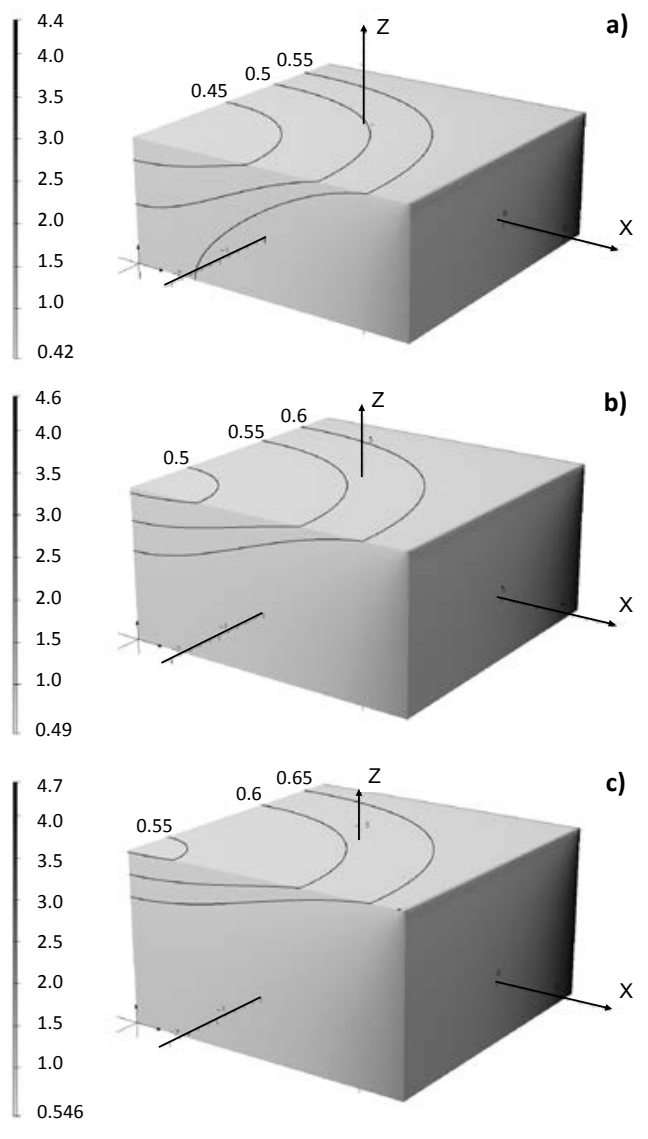

Fig. 4. Variations of $-B_{z} / \mu_{0} H_{z}$ inside the studied samples at room temperature, before the exposure to elevated temperature. The heights of the modelled magnets are $4.1 \mathrm{~mm}$ (a), $4.9 \mathrm{~mm}$ (b) and $5.6 \mathrm{~mm}$ (c) corresponding to an average $P_{c}$ of 1.0 (a), 1.2 (b) and 1.4 (c). Models include one eighth of the samples. The upper corners on the right-hand side are the actual corners of the magnet and the lower corners on the left-hand side are the centres of the magnets. The models describe the samples produced from material $\mathrm{B}$.

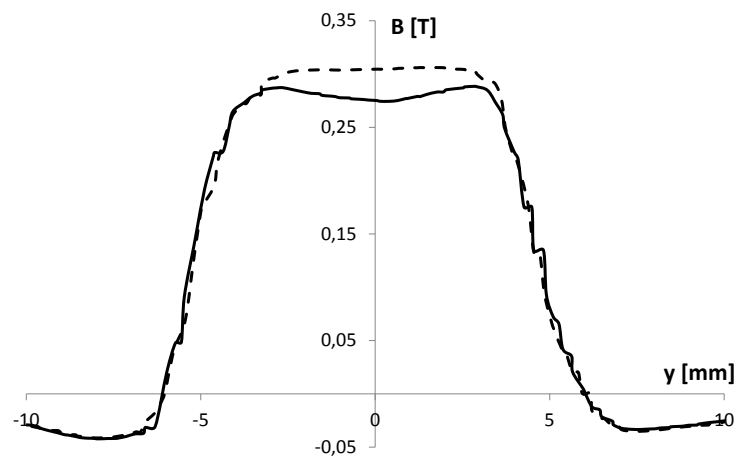

Fig. 5. Scanned magnetic flux density on the surface perpendicular to the magnetization direction $(Z)$ of a sample from material $\mathrm{B}\left(\mathrm{P}_{\mathrm{c}}=1.0\right)$ : before the stabilization heat treatment (dashed line) and after the treatment (solid line). Scanning was performed about $0.2 \mathrm{~mm}$ from the magnet surface.

As the partial demagnetization of the permanent magnets thermally stabilized in open circuit condition occurs at a certain location of the magnet, the stabilization does not necessarily cover the whole magnet volume. This might cause problems if the magnetic circuit is different in the application.

\section{Conclusions}

The effects of stabilization heat treatment on the timedependent demagnetization of sintered $\mathrm{NdFeB}$ magnets were studied. According to the results, the following five conclusions can be drawn:

1) Sintered $\mathrm{NdFeB}$ magnet materials showing a square $\mathrm{J}(\mathrm{H})$ curve $(\mathrm{SF}>0.97)$ do not need any stabilization treatment.

2) $\mathrm{NdFeB}$ material following rounder $\mathrm{J}(\mathrm{H})$ curve shows a stabilization effect. The polarization is found to be at lower level, but stable in pre-aged magnets over a certain period of time. The principle is that the same partial demagnetization that occurs over time in nonstabilized magnets, is induced in the magnets by the preageing treatment.

3) The temperature and duration of the pre-ageing treatment can be optimized so that the partial demagnetization is sufficient, ensuring stability over the required time, but not too heavy to cause any excess losses.

4) The pre-ageing treatment should be performed in similar magnetic conditions to those the magnets will face in the application. Stabilization treatment performed in open circuit condition does not stabilize magnets uniformly.

5) The $P_{c}$ calculated from the dimensions of the magnet is only an average value for the sample. In fact, the $P_{c}$ varies significantly inside the magnet.

\section{Acknowledgements}

This work was supported by the Finnish Cultural Fund, the Emil Aaltonen Foundation, the Ulla Tuominen Foundation, the High Technology Foundation of Satakunta, and the European Regional Development Fund.

\section{References}

1. T. Bizen, Y. Asano, T. Hara, X. Marechal, T. Seike, T. Tanaka, H. Lee, D. Kim, C. Chung, H. Kitamura, Nucl. Instr. and Meth. A 515, 850-852 (2003)

2. H. Mildrum, M. Hartings, K. Wong, K. Strnat, IEEE Trans. Magn. 10, 723-725 (1974)

3. J. Liu, M. Walmer, IEEE Trans. Electron Dev. 52, 899-901 (2005)

4. M. Haavisto, H. Kankaanpää, M. Paju, IEEE Trans. Magn., 47, 170-174 (2011)

5. M. Haavisto, H. Kankaanpää, T. Santa-Nokki, S. Tuominen, M. Paju, (to be published)

6. D. Branagan, M. Kramer, Y. Tang, R. McCallum, J. Appl. Phys. 85, 5923-5925 (1995)

7. R.J. Parker, Advances in Permanent Magnetism, (John Wiley \& Sons, 1990)

8. M. Haavisto, M. Paju, IEEE Trans. Magn. 45, 52775280 (2009) 